\title{
The Socio-Economic Impacts of Tourism Development in Sierra Leone: A Pilot Study
}

\author{
Alpha Thullah, ${ }^{1, ~ *}$ Hongna Liu ${ }^{2}$ \\ ${ }^{1}$ College of Tourism and Cuisine, Harbin University of Commerce, Harbin City, People's Republic of China \\ ${ }^{2}$ Business School, Harbin University of Commerce, Harbin City, People's Republic of China
}

Email address:

athullah@yahoo.com (A. Thullah)

${ }^{*}$ Corresponding author

To cite this article:

Alpha Thullah, Hongna Liu. The Socio-Economic Impacts of Tourism Development in Sierra Leone: A Pilot Study. European Business \& Management. Vol. 6, No. 6, 2020, pp. 128-135. doi: 10.11648/j.ebm.20200606.11

Received: October 31, 2020; Accepted: November 16, 2020; Published: November 27, 2020

\begin{abstract}
Tourism is a fast-growing industry, and one of the most vital sectors that drive the economic growth of a nation. This current work investigates the socio-economic impact of tourism in Sierra Leone. Therefore, the objectives of this research are to (1) analyze the contribution of tourism to national employment and poverty alleviation (2) analyze the contribution of tourism to the local economy (3) assess the impacts of tourism on destination regions in Sierra Leone. A total of 130 respondents from different works of life are targeted for this study. Results revealed that tourism have provided employment opportunities for many people especially youths. However, the nature of employment ranged from full time to part time. Tourism has also help many locals to establish business enterprises to meet the needs and demands of tourists. This has contributed to local economic growth in most part of the country. Both positive and negative impacts of tourism were identified on this current study. The positive impacts included cultural exchange between tourists and local people, infrastructural development in tourist destination communities or areas, and local currency flow. Soaring crime rates, cultural invasion, high cost of living are some of the negative implications of tourism identified by respondents.
\end{abstract}

Keywords: Development, Impact, Socio-economic, Sierra Leone, Tourism

\section{Introduction}

Tourism is seen as a poverty alleviation, economic diversification and inter-cultural strategy in most regions of the world. It had been described as one of the fastest-growing industry in terms of revenue generation and employment opportunities [1]. The revenue generation emanating from international tourism is roughly 1.5 trillion USD annually [2]. Many countries have recorded huge socio-economic benefit from the tourism sector, and thus have prioritized tourism as a useful tool to spur economic growth. For example in Tanzania, an earlier report suggested that the contribution of tourism in revenues was US $\$ 2.1$ billion (i.e. 4.7 percent of total GDP), provided 470,500 jobs, contributed total export earnings of approximately US \$2,446.6 million, and US\$ 1.2 billion investment in 2016 [3]. Also in Thailand, foreign earning from tourism resulted in the creation of approximately 2.4 million jobs in 2015 [4].
Statistic from the 2018 Sierra Leone Integrated Household Survey reveals that income poverty is still high, especially in rural areas [5]. The World Bank Group in 2018 outlined that in order to prevent the Sierra Leone economy from exogenic shocks, the country must consider diversifying its economy and create poverty-alleviating jobs outside of agriculture and the mining sector [6]. Thus, the Government of Sierra Leone has considered tourism as a priority sector for economic diversification. Sierra Leone is well fit to become an international tourism destination due to its excellent climate, beautiful beaches and parks, rich culture and nice people forested mountains and among others [7]. The tourism industry has experienced major growth in recent years. The development of an international tourist's destination will help to solve some of the problems of job scarcity to certain level. Local businesses such as hotels, airlines, and transportation will create new jobs and generate income for the country which is drivers for economic growth [8]. Therefore, there is a need for the government to diversify the 
country's economy in a sustainable way through investment in tourism [9].

Because tourism is a booming industry in the world, the industry has been at the core of a wide array of research. For example, a recent study assessed resident perception of tourism in Iran [10]. Another study used a gender approach to assess the perfection of people on tourism's impact and employment opportunities in the tourism industry in Jordan [11]. Furthermore, the economic and social ramifications of tourism on destination regions have been a thematic area of increasing scholarly investigation worldwide. For example the relationship between tourism and economic growth in India has been reported [12]. A new study has investigated the relationship between tourism specialization, economic growth, and human development in Poland [13]. Gnanapala and Sandaruwani studied the socio-economic impacts of tourism development and their implications on local communities in Sri Lanka [14]. In a similar vein, Khandare and investigated the social and cultural impact of tourism development in Thailand [15].

Africa is a home to myriad natural and cultural resources that are of high tourist attraction, as noted by the increasing figures of tourist's visits to the continent in recent years. The continent has recorded a handful of studies on tourism. For example, the socio-economic and environmental impacts of tourism development have been well documented in Botswana [16]. An earlier study evaluated the economic potential of tourism in Tanzania [17]. In Ethiopia, the impact of tourism on livelihood diversification outcome was recently reported [1]. In Sierra Leone, studies on tourism are rare as the industry has not attracted a great research interest. However, there are few existing studies identified in the wider literature. For example, Betts investigated the role of tourism in Sierra Leone's development [18]. Shakya conducted a competitiveness assessment on tourism in Sierra Leone [7]. Kongoley-MIH investigated the factors that inhibit the development of tourism in Sierra Leone after the civil war [19]. The study of Jackson and Tamuke used Box-Jenkins ARIMA models to predict tourists' arrival in Sierra Leone [20]. To the best of our knowledge, there is no existing literature on the socio-economic impact of tourism in Sierra Leone. This study therefore seeks to fill in the literature gap in the tourism industry in Sierra Leone. The overriding aim of this study was to access the socio-economic impacts of tourism development in Sierra Leone. The specific objectives were to (1) analyze the contribution of tourism to national employment and poverty alleviation (2) analyze the contribution of tourism to the local economy (3) assess the impacts of tourism on destination regions in Sierra Leone. This study is important in the sense that it will help the government of Sierra Leone to formulate and review policies on socio-economic issues around the tourism sector. Non-governmental Organizations (NGOs) and international partners, local businesses and potential investors will find this work meaningful as it will present relevant information to potential investors in Sierra Leone.

\section{Materials and Methods}

\subsection{Description of Study Area}

The current study was conducted in Freetown, Bo, Kenema, Makeni and Portloko in Sierra Leone. Freetown is located on the Western Area of Sierra Leone, and it is the capital city of the country. Further, Bo, Kenema, Makeni and Portloko are the regional headquarter towns for the Southern, Eastern, Northern and North-East regions respectively. These areas were taking as representative sample of Sierra Leone considering hospitality industries and other touristic attraction centers are found therein.

\subsection{Study Population}

The populations targeted by the study were civil servants from the Ministry of Tourism, Hotels and beach owners/managers, staff from the Local District Council, National Revenue Authority (NRA), Statistic Sierra Leone (SSL) and other stakeholders who have a stake in the hospitality industry. The number of participants in the study were: Mankeneh community (10 respondents), Manonkoh community (10 respondents), Mayoloh community (10 respondents), the Ministry of Tourism (7 civil servants), hotel/beach managers ( 7 respondents), Local District Council (7 staff) the Nation Revenue Authority (7 staff), Statistic Sierra Leone (7 staff), and 65 stakeholders from the tourism industry in Sierra Leone who were randomly selected. A total of 130 respondents were considered for this study.

\subsection{Data Collection Methods}

\subsubsection{Questionnaires Approach}

Questionnaires were administered to respondents who could not read and write, and who have no access to the internet. On the other hand, the questionnaires were sent to respondents via Google form for respondents who could read, write, and have access to the internet. This method helped the authors to reach many people and got responses from places they could not reach.

\subsubsection{Interview}

Close ended questions were used during the method, and it proved to be very efficient as respondents were able to give accurate answers on the topic. Also structured interviews were conducted for respondents that made it easy to compare and evaluate respondents' answers in a most objective and fair way.

\subsubsection{Data Analysis}

Google form has the ability to analyse responses in real time. However, since we used both Google form and printed questionnaires, the final analyses was done using Statistical Package for the Social Sciences (SPSS). The software was used to draw tables, descriptive ratio statistics, and charts. 


\section{Result and Discussion}

\subsection{Employment Opportunities Available in the Tourism Industry in Sierra Leone}

Respondents were asked about tourism related employment opportunities. Results obtained from them showed that 59\% strongly agreed that tourism have provided job opportunities for local residents, where as $35 \%$ agreed to the same view. However, $4 \%$ of the respondents had reservation about the question that was posed to them, thus remained neutral; while $1 \%$ disagreed and $1 \%$ strongly disagreed. The contrasting responses recorded herein might be as a result of the employment leakages that characterized the tourism sector wherein local residents are often neglected over non-local residents. The lack of requisite skills could be another challenge local residents would encounter in gaining employment in the tourism industry. It is Important to note that the tourism industry could only grow or develop if good quality human resources is employed and sustained overtime [21].

If local residents lack the required skills, it may result to poor condition of service including poor salary or wages. For example in the current study $54 \%$ of the respondents stated that local resident were poorly paid by the tourism business operators. While $32 \%$ of respondents did not subscribe to the view that lack of skills could lead to poor employment conditions, $14 \%$ did not vent out their opinions, thus remained neutral. However, a recent study asserted that local residents normally lack the technical know-how and the marketing skills that were mostly required in modern tourism development. Consequently they are usually disadvantaged in terms of rights and power [22]. In our study, most of the job opportunities available in the tourism industry for the locals are hut building, art and craft making, safety officers, securities, cleaning of the beach areas and tour guide. Similarly, a study in Botswana reported that locals working in the tourism industry have low-grade jobs such as cleaners, drivers, cooks, watchmen, with only a handful holding managerial positions [16].

The type of skills could also determine the nature of employment in the tourism industry whether it is full time, part-time or seasonal. In Sierra Leone, there is a handful of tourism activities that are seasonal and therefore the employment opportunities around them are the same. From figure 1, 27\% strongly agreed and $51 \%$ agreed to the seasonality nature of the employment opportunities in the tourism industry. Further, 2\% strongly disagreed and $9 \%$ disagreed that tourism related jobs are seasonal. These latter set of respondents have the opinion that the tourism industry provides full time employment. In spite of these mix assertion, $11 \%$ of respondents remained neutral since they could not answer the question. It is important to note that some of the respondents interviewed were employees working in the tourism sector for the Government of Sierra Leone on full time basis. Regardless of the employment typology, the literature acknowledges that the employment challenges in the tourism sector are unstable employment, and poor condition of service [21].

Because of the employment typology in tandem with other factors, tourism industry may provide more jobs for non-locals more than local residents and vice versa. However, this may depend on the employment status, and skill level of local residents. The current study has shown $67 \%$ of the respondents agreed that tourism creates employment opportunities more for locals than non-locals. This is in agreement with a previous study in Sri Lanka that reported $52 \%$ of the locals were engaged in tourism-related jobs [14]. In our study, $18 \%$ of the respondents could not give a clear response, thus remained neutral. A handful $(15 \%)$ of the respondents stated that tourism provide more jobs for non-locals than local residents.

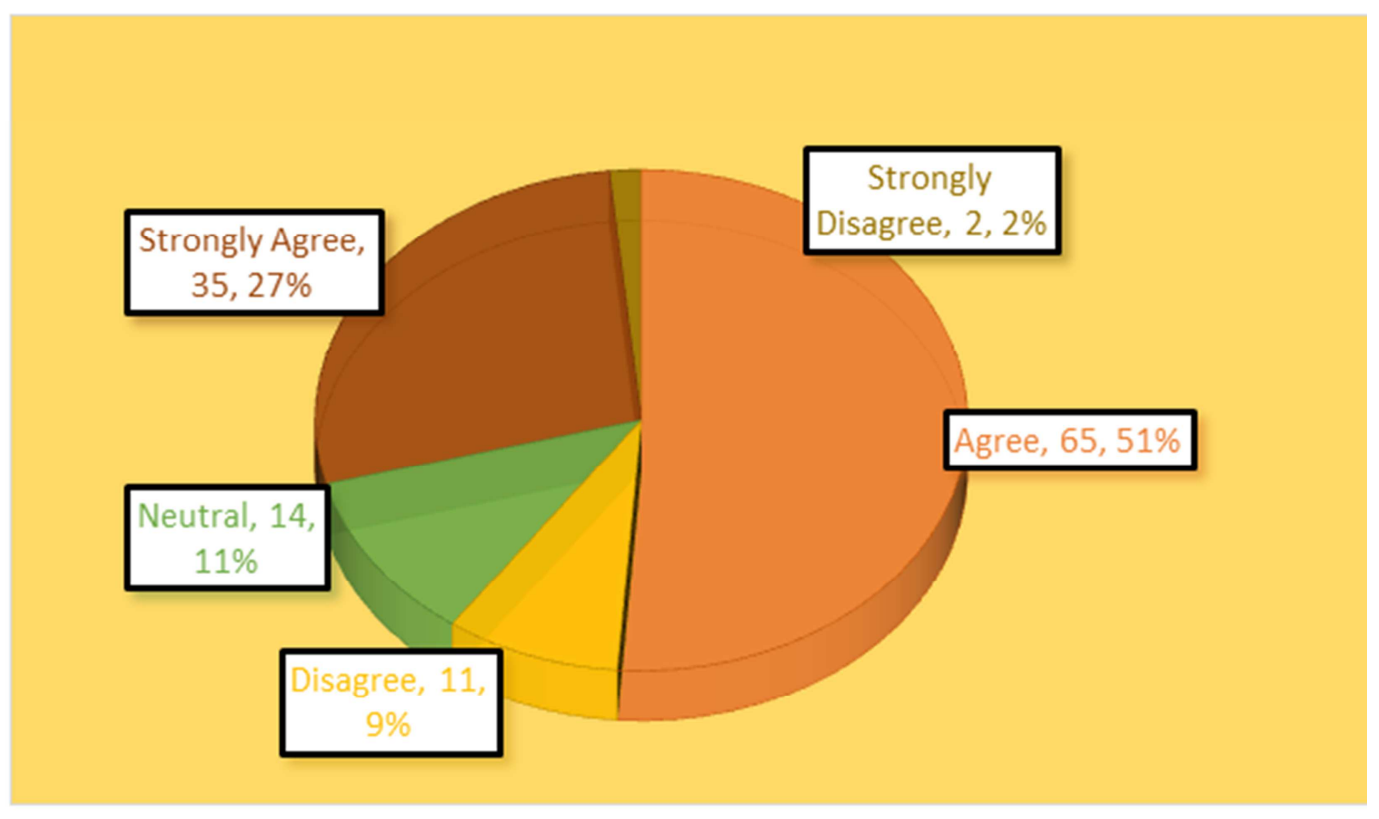

Figure 1. Seasonality of tourism related jobs. 
Table 1. Stakeholders response on local and outsiders employment.

\begin{tabular}{|c|c|c|c|c|c|c|c|}
\hline \multirow{3}{*}{$\begin{array}{l}\text { What is the employment ratio between outsiders and } \\
\text { locals in your facility? (For hotel/beach managers) }\end{array}$} & \multicolumn{7}{|c|}{ Respondents Ratio } \\
\hline & $1^{\text {st }}$ & $2^{\text {nd }}$ & $3^{\text {rd }}$ & $4^{\text {th }}$ & $5^{\text {th }}$ & $6^{\text {th }}$ & $7^{\text {th }}$ \\
\hline & $40 \%: 60 \%$ & 25\%: $75 \%$ & $30 \%: 70 \%$ & $40 \%: 60 \%$ & $10 \%: 90 \%$ & $35 \%: 65 \%$ & $10 \%: 90 \%$ \\
\hline $\begin{array}{l}\text { What is the ratio of employment of top positions between } \\
\text { locals and outsiders (for hotel/beach managers) }\end{array}$ & $35 \%: 65 \%$ & $25 \%: 75 \%$ & $40 \%: 60 \%$ & $50 \%: 50 \%$ & $35 \%: 65 \%$ & 10\%: $90 \%$ & $15 \%: 85 \%$ \\
\hline $\begin{array}{l}\text { What percentage of the total employment in Sierra Leone } \\
\text { comes from tourism industry? (For SSL/NRA/Local } \\
\text { council) }\end{array}$ & $5 \%$ & $5 \%$ & $10 \%$ & - & $9 \%$ & - & - \\
\hline $\begin{array}{l}\text { What is the estimated employment rate in Sierra Leone? } \\
\text { (For SSL/NRA/Local council) }\end{array}$ & $30 \%$ & - & $40 \%$ & - & $35 \%$ & - & - \\
\hline
\end{tabular}

*NB: $1^{\text {st }}-7^{\text {th }}$ means the number of respondent in each sector, - means respondents did not provide answer to the question. NRA=National Revenue Authority, $\mathrm{SSL}=$ Statistics Sierra Leone.

The issue of job provision for locals might create conflict in tourism destinations as locals may feel marginalized in tourism related employment schemes. Here, we analyzed the information that was obtained from specific institutions such as District Council's staff, National Revenue Authority, Statistic Sierra Leone, Beach Managers as well as Hotels Managers. Seven respondents from each of the aforementioned institutions were interviewed and their responses are showed in table 1 . They were asked if they prefer allocating jobs to locals than non-locals. The table shows that locals are more employed in the tourism enterprises compared to non-locals. The employment ratio in percentages indicates more than $60 \%-70 \%$ respondents were in favour of the locals. This maybe as a result of the availability of many jobs in the hospitality industry which does not requires high skilled labour force.

The above table shows that $60-70 \%$ of the top cadre or managerial positions in the surveyed tourism enterprises are directed to non-locals. It is obvious that top managerial positions need highly trained and experienced people that the locals do not possess. Even if the owners of the facilities may want to employ the locals, the problem is their lack of knowledge about managing a tourism enterprise.

\subsection{The Contribution of Tourism to the Local Economy}

Tourism is instrumental in the setting up new small and medium scale enterprises spur the growth of the existing businesses in destination regions [14]. Tourism businesses can be classified into four service areas. They are "accommodation, food and beverage services, transportation and excursions services and crafts and shopping items" [14]. From figure 2, 53\% of the respondents agreed that tourism promote entrepreneurial attitude among locals. Further, $37 \%$ of the respondents strongly affirmed their assertions. The result obtained here accord well with an earlier study in Sri Lanka where majority (66\%) of the locals were either directly or indirectly engaged in tourism business/self-employment activities [14]. Result obtained from respondents indicate that majority of them that live in tourist attraction areas normally commence business activities as the inflow of tourists' increases. Similarly, a study in Malaysia found that as the number of tourists increase, lots of local nationals engage in transportation services, handicraft production and sales, hotels and hospitality provision, food and beverage, among other services in order to meet the demands of tourists [23]. Further in Figure 2, 8\% of the respondents remain neutral while only $2 \%$ disagree with the assertion. The neutrality and disagreement may come from the fact that many local residents do not engage in business activities due lack of capital.

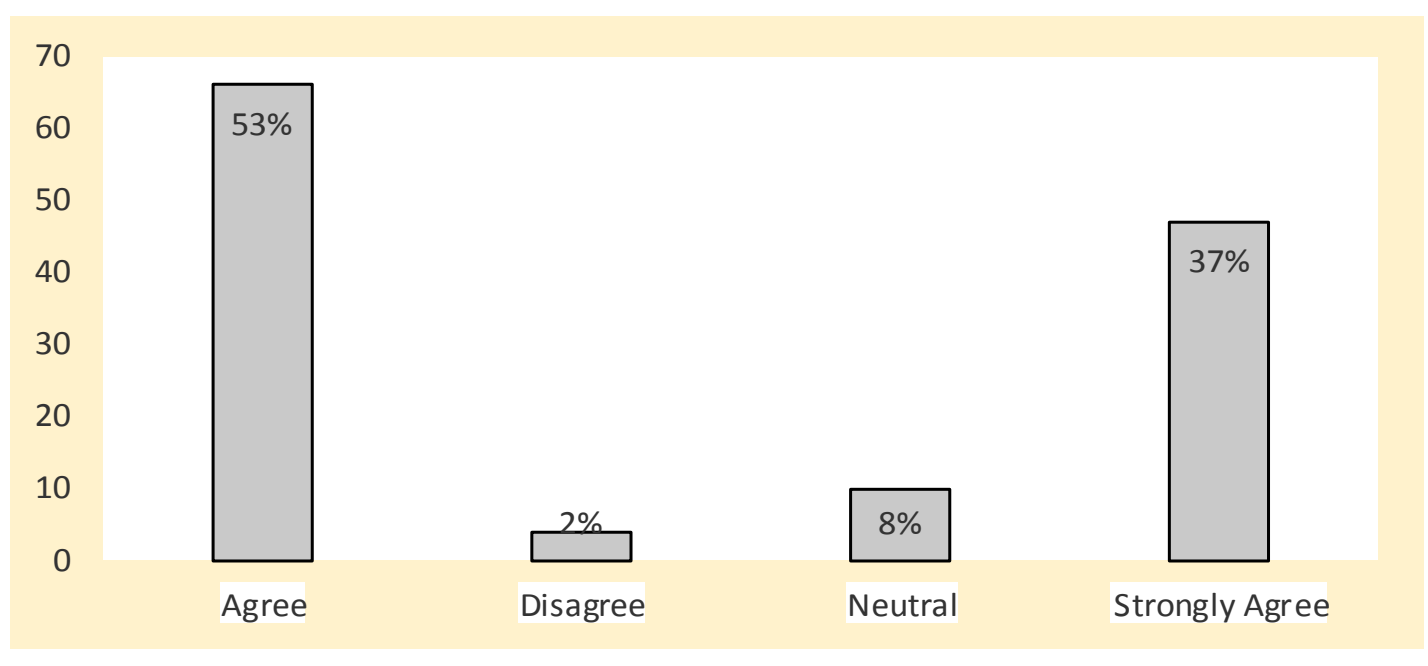

Figure 2. Tourism enhance entrepreneurial attitude among the local residents. 


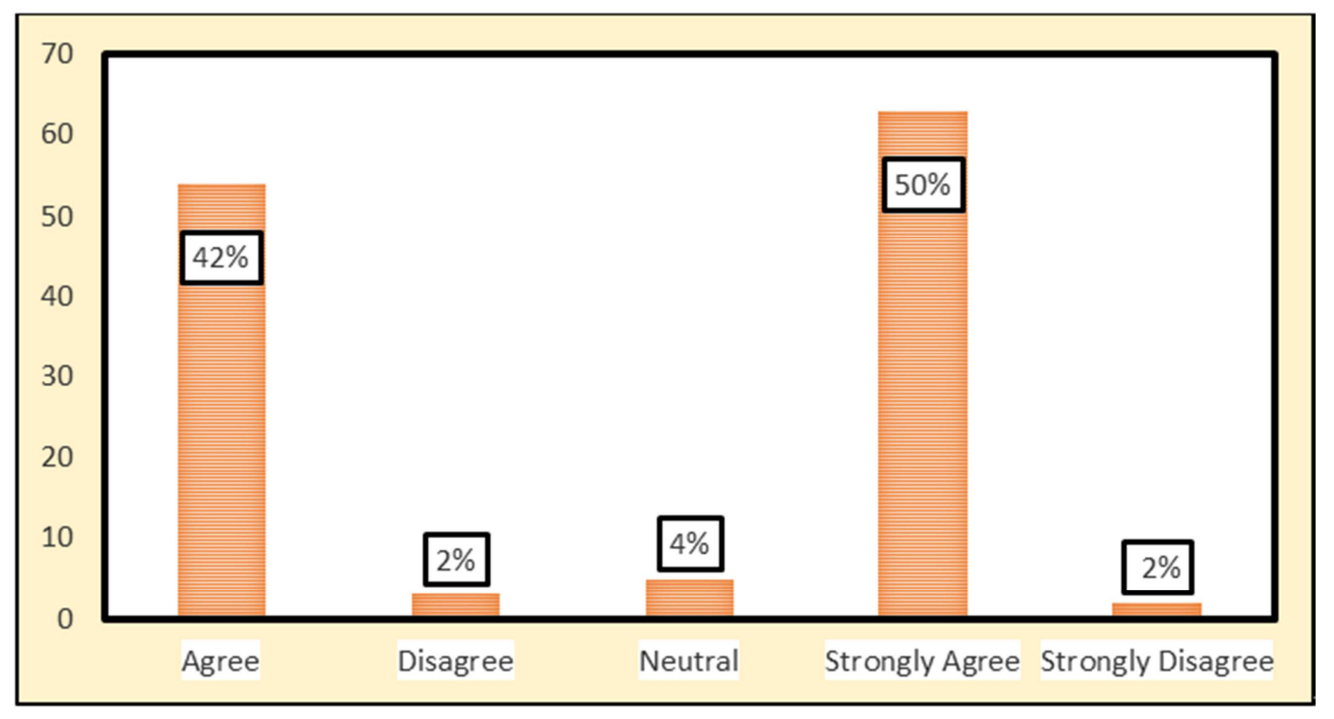

Figure 3. Tourism creates new markets for local products.

From figure 3, $50 \%$ of the respondents strongly agreed while $42 \%$ agreed that tourism activities create market for their products. Tourism activities are good market source for the local produces. Many local people have huge market during the peak tourism season because of the high arrival of tourists. Tourism create many business opportunities through the promotion of tourism related businesses, products, and services as well. If the business opportunities in tourism show an increase trend, there is a high tendency for a corresponding increase in the diversification of products and development of new product [1]. Afthanorhan and colleagues used social exchange theory in assessing public perception of tourism impact in Terengganu Malaysia [24]. They found that local residents held a firm conviction that the presence of tourism creates new business opportunities for them. From figure 3, $4 \%$ of the respondents remain neutral, $2 \%$ disagreed while another $2 \%$ strongly disagreed that tourism create new markets for local products. Few of the respondents do not agree with this assertion of market opportunities due to the fact that some tourists do not normally buy local goods. Taken as a whole, results showed that tourism had increased the earnings of majority ( $93 \%$ ) of the respondents as opposed to $7 \%$ of respondents who stated otherwise.

An increase in the number of tourists' arrival means an increase in the foreign currency flow. Tourists normally come with foreign currencies which they changed to the local currency to help them in buying assorted things. The change of foreign currencies by locals increase the flow of foreign currency which is good for the country's economy since the government can use it for the balance of payment. Majority of the respondents $(91 \%)$ stated that tourism provides foreign currency inflow, $3 \%$ stated never and $6 \%$ could not provide response to the question and thus remain neutral. In some cases tourists give foreign currencies to locals for free as a sign of generosity.

\subsection{Tourism Impacts}

The tourism industry has created both positive and negative impacts on tourist designated communities worldwide. The type, scale and magnitude of impacts vary from one country to another depending on national realities. The study of Jaafar et al reviewed the perceived positive and negative social effects of tourism development [23]. There are factors that could influence public perception of tourism impacts and these have been detailed by other researchers [10]. In the current study, respondents' perceived tourism impacts were assessed. The results revealed respondents stated both positive and negative impacts of tourism. It is important to note that public perception of tourism impact could predict their attitudes and behaviour toward tourism development [10].

\subsection{Positive Impact of Tourism}

Sierra Leone has a unique culture and the display of traditional secret societies, magic is part of the country's culture. When tourist visits, locals normally entertained them by displaying different cultural activities. There are evidence of tourists taking part in these activities, as well as taking of photos. This helps in selling out the culture of Sierra Leone to tourists. Respondents stated that most tourists are fond of interacting with locals, and making new friends. Locals stated that tourists normally introduce new games to them, exchange food and clothes with locals and discuss a range of cultural differences including marriage, burial ceremonies, and religion among others. This is a unique form of promoting cultural exchange between locals and foreigners. Result showed $90 \%$ of respondents stated tourism promotes cultural exchange between foreigners and locals, whereas $5 \%$ stated otherwise and $6 \%$ reserved their opinion. The visit by tourists to local communities influence the social lifestyle of local communities as $88 \%$ of respondents agreed that tourism have changed their social values. Similar to our finding, Mensah and Amuquandoh found that tourism activities have brought improvements to the quality of life for poor residents in Ghana [25]. In contrast, $6 \%$ of respondents in the current study remain neutral, $6 \%$ disagreed that tourism have 
improved upon their quality of life, and the result is in line with a study in China [22].

Because of tourism business, Sierra Leone has seen a growing infrastructural improvement in areas where tourists visit. A total of $90 \%$ of the respondents stated that tourism brings development to the locals through infrastructure. Similarly, a study in Malaysia reported respondents mentioned roads, hospitals, schools, parks, and restaurants as some of the infrastructural improvements due to tourism [23]. In contrast, $8 \%$ of respondents in our study hold on to their opinions, while $2 \%$ disagreed to the contribution of tourism to infrastructural development. As tourism becomes a popular economic diversification strategy in Sierra Leone, new recreational facilities have been established to meet the needs and demands of tourist. Most of the respondents (88\%) stated that tourism development has increased the number of recreational opportunities for the local residents, and $12 \%$ stated never. The mix responses may likely be as a result of the geographic location of the respondents. Respondents who live in big cities and towns may agree with the increase in recreational facilities due to tourism as the construction or establishment of night clubs, bars and restaurants, hotels and swimming pools have been on the rise in urban areas. However, these facilities are uncommon in rural areas where tourists visit. This is perhaps the reason (s) for the divided opinion on tourism impacts among respondents.

\subsection{Negative Impact of Tourism}

\subsubsection{Impacts on Norms and Tradition}

Despite the positive impact of tourism in destination regions, there are negative impacts associated with the industry as well. There is a tendency for incoming tourists to influence the norms and traditions of the communities they visit. In most local communities in Sierra Leone, it is odd for lovers or even married couple to display affection such as kissing in public places. However, public expression of love is a common practice among tourists especially those who bring along their partners. Since it is uncommon among locals, some of the respondents interviewed in this study stated that young people in local communities might copy this public attitude towards love relationship (e.g. kissing) especially at a time most young people are imitating western lifestyle.

There are beautiful waterfalls and beaches along rivers in most local communities across Sierra Leone. These water bodies are normally used for swimming, bathing, among other uses. According to the local tradition of these communities, there are separate points where males and females should use these resources. For example, it is forbidden in most communities for males and females to swim or bath in the same place. Nowadays, as the tourism industry keeps expanding, tourist do not tend to comply with some of these traditions and norms. Male can wear swim suit and females Biki and other transparent beach clothes and use the beaches, waterfalls together. With the exception of urban areas, local communities deemed this practice by tourists as odd according to their tradition. The literature acknowledges that because of the income and revenue generation from tourism is much higher than other local feasible livelihood options, tourism is a widely accepted industry by local regardless of it negative ramifications on local communities [15].

Even tourism enhance cultural exchange between locals and foreigners, some see this exchange as a practice that is eroding their cultural foundation. From our analysis, $48 \%$ of the respondents rejected the notion that tourism causes cultural invasion. However, $40 \%$ of the respondents agreed it has negatively impacted some norms and traditions especially in local communities. Our findings for those that agreed is similar to a study in Sri Lanka that reported respondents agreed that tourism development has caused negative social and cultural effects to tourism affected local communities [14]. Nevertheless, $12 \%$ of respondents in our study could give a clear response on this aspect and therefore remain neutral. It is important to note that tourism impacts are not always positive, there can be negative ones as well especially on local communities which scale and magnitude cannot be assesses by mere observation [24].

\subsubsection{Negative Social Impacts of Tourism}

Respondents stated that the high presence of tourists is associated with an increase in prostitution rate among local girls and women, and drug use for sexual enhancement and other purposes. Some of the respondents explained that some local youths normally sell drugs such as cannabis sativa (weed) to tourists - a substance consider as illegal to smoke or use in any form in Sierra Leone. Some of the respondents explained that local criminals come around tourist areas such as beaches, bars and restaurant to perpetuate crimes such as pick pocketing, snatching phones of tourists and even locals. There are cases wherein both tourists and locals have been robbed of their valuables by local gangs during high tourists' period. This also creates a problem for people who live in these touristic areas.

From our analysis, $32 \%$ of respondents stated that tourism is not associated with social problems such as crime, drug use, and prostitution. They stated that these problems are endemic in the social fabric of the country. In a similar fashion, an earlier study in Malaysia found most of the study participants did not agree with the negative impact of tourism [23]. In contrast, $52 \%$ of respondents in the current study asserted tourism is responsible for the social problems mentioned above, whereas $16 \%$ could state their views or opinions on the question. Gnanapala and Sandaruwani stated tourism has the tendency for causing more negative downside mainly by decreasing the socio-cultural values of touristic regions [14].

\subsubsection{Negative Impact on Living Cost for Locals}

In tourist attraction areas, there is high tendency for local traders and business people to skyrocket the prices of commodities because of the high arrival of tourists. During this period, no distinction is made in prices for locals or tourists. This high cost of living affects local people, because tourists normally brought with them enough money to meet their needs and demands. 




Figure 4. Impact of tourism on living expenditure.

From figure 4, 52\% of the respondents agreed and 21\% strongly agreed that tourism increased the living expenditure of the locals. However, a total of $10 \%$ held an opposite view (disagreed and strongly disagreed) while 17\% reserved their opinions on the matter. Hateftabar and Chapuis asserted that if local residents opined that tourism positive impacts are more than the negative ones, the outcome of cost-benefit analysis will be positive and they will throw their support for tourism development and vice versa [10].

\section{Conclusion and Policy Recommendations}

In Sierra Leone, the tourism industry is key to long-term growth and competitiveness. The result of this study revealed tourism has provided employment opportunities for locals. The sector has promoted cultural exchange between local and foreigners. There are both positive and negative impacts stated by respondents which scale and magnitude cannot be elucidated here. Tourism if taken as priority has tremendous potential to lift lots of people out of poverty in Sierra Leone. Therefore it is recommended that the hopes and aspirations of the poor and marginalized should be factored in the formulation or review of national tourism policies and legislation. For example China has recorded a massive reduction in the number of people living in poverty due to formation and implementation of the "Poverty Alleviation Tourism Policy (PATP)" [22]. It is inevitable that tourism have negative impacts on destination regions. An ideal approach is to raise awareness among locals on the possible direct and indirect socioeconomic impacts of tourism on their local community [10]. A community centered approach will help local communities to be aware of tourism and its products. The Government of Sierra Leone and its development partners should more focus on pro-poor tourism, community-based tourism, eco-tourism and sustainable tourism that give priority to local communities' economic and social sustainability in order to solve tourism related problems such as unemployment among locals. Lastly, the government should establish nationwide arts and cultural training centers where locals will be trained to fit in to the modern tourism and hospitality needs. Also, locals should be trained on marketing and business planning so as to enable them to sustainably start and managed local tourism related businesses.

\section{References}

[1] Bires, Z., and Raj, S. (2020). Tourism as a pathway to livelihood diversification: Evidence from biosphere reserves, Ethiopia. Tourism Management 81, 104159 https://doi.org/10.1016/j.tourman.2020.104159.

[2] Kozhokulov, S., Chen, X., Yang, D., Issanova, G., Samarkhanov, K., and Aliyeva, S. (2019). Assessment of Tourism Impact on the Socio-Economic Spheres of the Issyk-Kul Region (Kyrgyzstan). Sustainability, 11, 3886; doi: 10.3390/su11143886.

[3] World Travel and Tourism Council (WTTC) - Tanzania (2017). "Travel and Tourism Economic Impact 2017, Tanzania". Travel and Tourism Council, London, UK.

[4] Chulaphan, W., and Barahona, J. F., (2018). Contribution of disaggregated tourism on Thailand's economic growth. Kasetsart Journal of Social Sciences 39, 401-406. http://dx.doi.org/10.1016/j.kjss.2017.07.012.

[5] Government of Sierra Leone (2019). Sierra Leone's medium-term national developmen plan 2019-2023.

[6] Matias, A., Nijkamp, P., and Sarmento, M. (2001). Tourism Economics, Impact Analysis. Springer Heidelberg Dordrecht London New York.

[7] Shakya, M. (2009). Competitiveness Assessment of Tourism in Sierra Leone A Cluster-Based Approach. Policy Research Working Paper 5083 Available at http://documents1.worldbank.org/curated/en/78675146810405 9940/pdf/WPS5083.pdf. 
[8] World Travel and Tourism Council (2017). Travel \& Tourism Global Economic Impact \& Issues.

[9] World Bank Group (2018). Sierra Leone Economic Update; Reviving Urban Development the Importance of Freetown for the National Economy Edition No 1.

[10] Hateftabar, F., and Chapuis, J. M., (2020). How resident perception of economic crisis influences their perception of tourism. Journal of Hospitality and Tourism Management 43, 157-168. https://doi.org/10.1016/j.jhtm.2020.02.009.

[11] Alrwajfah, M. M., Almeida-García, F., and Cortés-Macías, R., (2020). Females' perspectives on tourism's impact and their employment in the sector: The case of Petra, Jordan. Tourism Management 78, 104069. https://doi.org/10.1016/j.tourman.2019.104069.

[12] Ohlan, R. (2017). The relationship between tourism, financial development and economic growth in India. Future Business Journal 3, 9-22. http://dx.doi.org/10.1016/j.fbj.2017.01.003.

[13] Croes, R., Ridderstaat, J., Bąk, M., and Zientara, P. (2021). Tourism specialization, economic growth, human development and transition economies: The case of Poland. Tourism Management 104181. https://doi.org/10.1016/j.tourman.2020.104181.

[14] Gnanapala, W. K. A., and Sandaruwani, J. A. R. C. (2016). Socio-economic Impacts of Tourism Development and Their Implications on Local Communities. International Journal of Economics and Business Administration. 2 (5) 59-67.

[15] Khandare, V., and Phophueksanand, P. (2018). Social and Cultural Impact of Tourism Development in Thailand. International Journal of Research in Economics and Social Sciences, 8 (2).

[16] Mbaiwa, J. E. (2003). The socio-economic and environmental impacts of tourism development on the Okavango Delta, north-western Botswana. Journal of Arid Environments (2003) 54: 447-467 doi: 10.1006/jare.2002.1101.
[17] Kweka, J., Oliver, M., and Blake, A. (2003). The Economic Potential of Tourism in Tanzania. Journal of International Development, 15, 335-351.

[18] Betts, B. S. H. (2016). The Role of Tourism in the Development of Sierra Leone. American Scientific Research Journal for Engineering, Technology, and Sciences. 26 (4), 205-224.

[19] Kongoley-MIH, P. S. (2017). Factors That Inhibit the Development of Tourism in Sierra Leone after the Rebel War. International Journal of Scientific and Research Publications, 7, 1.

[20] Jackson, E. A., and Tamuke, E. (2020). Predicting Disaggregated Tourist Arrivals in Sierra Leone Using ARIMA Model. Theoretical and Practical Research in the Economic $\left.\begin{array}{lllll}\text { Fields, } & \text { [S. } & 1 .\end{array}\right], \quad 10 \quad$ (2), $132-142$, https://doi.org/10.14505//tpref.v10.2(20).06.

[21] Aynalem, S., Birhanu, K., and Tesefay, S. (2016). Employment Opportunities and Challenges in Tourism and Hospitality Sectors. J Tourism Hospit 5: 257. doi: 10.4172/2167-0269.1000257.

[22] Qin, D., Xu, H., and Chung, Y. (2019). Perceived impacts of the poverty alleviation tourism policy on the poor in China. Journal of Hospitality and Tourism Management 41, 41-50. https://doi.org/10.1016/j.jhtm.2019.09.004.

[23] Jaafar, M., Ismail, S., and Rasoolimanesh, S. M. (2015). Perceived Social Effects of Tourism Development: A Case Study of Kinabalu National Park. Theoretical and Empirical Researchers in Urban Management. 10, 2, 2015.

[24] Afthanorhan, A., Awang, Z., and Fazella, S. (2017). Perception of Tourism Impact and Support Tourism Development in Terengganu, Malaysia. Soc. Sci. 2017, 6, 106; doi: $10.3390 /$ socsci6030106.

[25] Mensah, E. A., and Amuquandoh, F. E. (2010). Poverty reduction through tourism: Residents' perspectives. Journal of Travel \& Tourism Research, 77. 